\title{
Bioassay Kits for Ecotoxicological Testing of Wastewaters with Nanoparticles
}

\section{Edward PC Lai}

Department of Chemistry, Carleton University, Ottawa, Ontario, Canada

Evaluation of complex wastewaters should include acute/chronic ecotoxicological tests [1] and the potential for endocrine disruption $[2,3]$ to complement the physicochemical characterization. The advantages of bioassay (with a bacterium, alga or crustacean) are simplicity, speed and low cost for monitoring toxicity over time. Its strongest attribute is usefulness as a primary screening test for a broad spectrum of toxicants. Several bioassay kits are commercially available, including the Lux-fluoro, Polytox, Microtox and Thamnotox kits that require no specialized equipment. A combined approach using instrumental methods for chemical analysis and bioassays for ecotoxicological testing would be extremely important to hazard/risk assessment of wastewater treatment plant discharges.

The Lux-fluoro test was developed for the rapid detection and quantification of environmental pollutants with genotoxic and/or cytotoxic potential [4]. This bacterial test system uses two different reporter genes whose products and reactions can be measured easily and simultaneously by optical methods. Genotoxicity is measured by the increase of bioluminescence in genetically modified bacteria which carry a plasmid with a complete lux operon for the enzyme luciferase from the marine photobacterium P. leiognathi. If the deoxyribonucleic acid (DNA) in these bacteria is damaged by a genotoxic chemical, the SOS promoter is turned on and the lux operon is expressed. Other genetically modified bacteria carry the gene for the green fluorescent protein from the jellyfish Aequora victoria downstream from a constitutively expressed promoter. These bacteria are fluorescent under common growth conditions. If their cellular metabolism is disturbed by the action of cytotoxic chemicals, the fluorescence decreases in a doseproportional manner. A temperature-controlled microplate reader capable of sequential reading of luminescence and fluorescence can be programmed for repeating the measurement cycle at $30^{\circ} \mathrm{C}$ from $10 \mathrm{~min}$ up to 8 hours of continuous incubation [5].

The Microtox assay is based on the luminescent mechanism of freeze dried Photobacterium phosphoreum or Vibrio fischeri [6]. If metabolic processes are changed upon cell damage by a toxic substance, a reduction in light output can be detected within 5 to 30 minutes. After correcting the effects of color and turbidity on bacterial light output measurements [7], an EC5O concentration can be calculated as a toxicity value for comparison against a control substance to evaluate relative toxicity [8]. Microtox is probably the most sensitive test that can be used in a screening phase. The test has recently been used to quantify the impact of storage time on toxic compounds formed in the electrochemical treatment of phenol. Chlorinated phenols exhibited little toxicity change while highly toxic benzoquinone exhibited $92 \%$ loss of its initial toxicity over 18 days [9].

Polytox is a 30 -minute rapid biological test for measuring the toxicity of raw water or wastewater to biological organisms. This blend of specialized microbial cultures, free of nitrifying microorganisms, provides a simple and economical test that eliminates the need for expensive instrumentation [10]. It is a cost-effective and nonpathogenic product that runs with a standard dissolved oxygen meter. Reliable, consistent results can be obtained in 30 minutes. The shelf life is, however, only 3 months from the date of product activation upon order.
Thamnotox bioassay with the crustacean Thamnocephalus platyurus [11] is cost-effective and culture maintenance-free. Test organisms are included in the kit as dormant eggs (or cysts) which can be hatched on demand, in 24 hours, to supply the biota. The assay is based on mortality of the test organisms, with calculation of the $24 \mathrm{hLC} 50$. A quality control test with a reference chemical provides for accuracy and reproducibility check. Minimal equipment is needed for test performance: dissecting microscope, small incubator and conventional laboratory glassware. The shelf-life of cysts is guaranteed for several months when stored properly, thereby reducing test scheduling constraints. Total performance time of the assay is approximately 1 hour. The Thamnotox kit is used in many laboratories worldwide for routine screening of chemicals. It is specifically sensitive to biotoxins produced by blue-green algae in environmental samples. Test results have shown significant correlation with organic load parameters and total suspended solids.

Nanoparticles (NPs) are increasingly applied in a diverse array of commercial, industrial and medical products due to their intrinsic properties. There is a pressing requirement for a comprehensive understanding of their hazard, which is a major research preoccupation for toxicologists [12]. Since early literature showed that very complex and unexpected interactions could occur between nanomaterials and biological systems, a wide spectrum of NPs varying in charge, composition, shape, size and solubility has been tested of their toxicity. Other than their ability to translocate from the site of deposition, there is no evidence that particles below $100 \mathrm{~nm}$ show any step-change in hazard from the conventional particle toxicology. Effort should be focused on measuring their toxicokinetics toward a better understanding of nano-specific risk assessment at the individual organism, tissue, cell and DNA levels. Toxic behavior of zinc oxide NPs at the subcellular level, for instance, has recently been reported [13] Treatment of isolated rat liver mitochondria with $\mathrm{ZnO}$ NPs resulted in collapse of membrane potential, swelling, depression of respiration, increase of inner membrane permeability to $\mathrm{H}^{+}$and $\mathrm{K}^{+}$, alterations of ultrastructure, release of cytochrome $\mathrm{c}$, and generation of reactive oxygen species. These results suggested a putative mechanism that $\mathrm{ZnO}$ NPs can lead to energy dissipation, oxidative stress and even apoptosis.

Dissolution of $\mathrm{ZnO}$ NPs plays an important role in the toxicity to aquatic organisms [14]. The effects of water chemistry such as $\mathrm{pH}$, ionic components, and dissolved organic matter (DOM) on the dissolution

*Corresponding author: Edward P.C. Lai, Department of Chemistry, Carleton University, Ottawa, Ontario, Canada, Tel: 613-520-2600; E-mail: edwardpclai@gmail.com

Received July 22, 2013; Accepted July 23, 2013; Published July 25, 2013

Citation: Lai EPC (2013) Bioassay Kits for Ecotoxicological Testing of Wastewaters with Nanoparticles. Biochem Anal Biochem 2: e139. doi: 10.4172/21611009.1000e139

Copyright: ( 2013 Lai EPC. This is an open-access article distributed under the terms of the Creative Commons Attribution License, which permits unrestricted use, distribution, and reproduction in any medium, provided the original author and source are credited. 
Citation: Lai EPC (2013) Bioassay Kits for Ecotoxicological Testing of Wastewaters with Nanoparticles. Biochem Anal Biochem 2: e139. doi: 10.4172/2161-1009.1000e139

Page 2 of 2

of nano- $\mathrm{ZnO}$ and its toxicity to Escherichia coli were investigated. The results showed that increasing $\mathrm{pH}, \mathrm{Ca}^{2+} / \mathrm{Mg}^{2+}, \mathrm{HPO}_{4}^{2}-$ and $\mathrm{DOM}$ reduced the concentration of free $\mathrm{Zn}^{2+}$ released and thus lowered the toxicity of $\mathrm{ZnO}$ NPs. Suspensions of cerium oxide, iron oxide and titanium oxide nanoparticles were tested for lead removal in water cleaning via adsorption processes [15]. Germination tests with tomato/lettuce/cucumber seeds and the Microtox assay were used to determine the toxicity of synthesized NPs, NPs after lead adsorption, and the supernatant after NPs separation. The $\mathrm{CeO}_{2} \mathrm{NPs}$ showed a high phytotoxicity while the $\mathrm{Fe}_{3} \mathrm{O}_{4} \mathrm{NPs}$ and $\mathrm{TiO}_{2} \mathrm{NPs}$ did not exhibit any toxicity.

Silica mesoporous nanoparticles are used more and more in oral drug delivery. Their cytotoxicity and genotoxicity on the HT29 human intestine cell line were studied by measuring cell viability, proliferation and global metabolism [16]. Besides conventional sulforhodamine B, flow cytometry, and $\gamma$-H2Ax foci approaches, real-time monitoring of cell proliferation was performed using an impedance-based system to ensure no interference. Experimental results showed that 25-nm and 100-nm $\mathrm{SiO}_{2}$ NPs induced a rather limited cytotoxic and genotoxic effects on HT-29 cells after a 24-h exposure. Interestingly, the higher the $100-\mathrm{nm} \mathrm{SiO}$ dose, the lower the cytotoxic/genotoxic effects. These data well illustrated the complexity in understanding the hazards of NPs for human health. Previous work had reported the effect of carboxyl functionalization of graphene in pacifying its strong hydrophobic interaction with cells and associated toxic effects [17]. Pristine graphene (contact angle $=162^{\circ}$ ) was found to accumulate on the cell membrane causing high oxidative stress leading to apoptosis, whereas carboxyl functionalized hydrophilic graphene (contact angle $=30^{\circ}$ ) was internalized by the cells without causing any toxicity.

Systematic evaluation of NPs toxicology in living systems was based on a determination of the number of NPs and of their toxicity factor [18]. Such a strategy was applied to the ingestion of citrate-capped gold nanoparticles by the model system Drosophila melanogaster. Using AuNPs as a reference toxicity standard, different regions in the multiparametric space of toxicity were defined to enable the classification of other nanomaterials, such as quantum dots and pegylated AuNPs. This approach may lead to important developments in risk assessment and regulatory approval of NPs in a wide range of applications.

\section{References}

1. Mendonça E, Picado A, Paixão SM, Silva L, Cunha MA, et al. (2009) Ecotoxicity tests in the environmental analysis of wastewater treatment plants: case study in Portugal. J Hazard Mater 163: 665-670.
2. Murray A, Ormeci B, Lai EP (2011) Removal of 17beta-estradiol (E2) and its chlorination by-products from water and wastewater using non-imprinted polymer (NIP) particles. Water Sci Technol 64: 1291-1297.

3. Miah M, lqbal Z, Lai EPC (2012) Rapid CE-UV evaluation of polypyrrolecoated magnetic nanoparticles for selective binding of endocrine disrupting compounds and pharmaceuticals by aromatic interactions, Analytical Methods 4: 2866-2878.

4. Baumstark-Khan C, Rabbow E, Rettberg P, Horneck G (2007) The combined bacterial Lux-Fluoro test for the detection and quantification of genotoxic and cytotoxic agents in surface water: results from the "Technical Workshop on Genotoxicity Biosensing". Aquat Toxicol 85: 209-218.

5. Peng S, Zhao M (2009) Lux-Fluoro assay for combined genotoxicity and cytotoxicity. Pharmaceutical Bioassays: Methods and Applications. Wiley 21.8: 427.

6. Fulladosa E, Villaescusa I, Martínez M, Murat JC (2005) Study of Cr(VI) and $\mathrm{Cd}(\mathrm{II})$ ions toxicity using the Microtox bacterial bioassay. Environmental Chemistry 725-734.

7. Ashworth J, Nijenhuis E, Glowacka B, Tran L, Schenk-Watt L (2010) Turbidity and color correction in the Microtox bioassay. The Open Environmental Pollution \& Toxicology Journal 2: 1-7.

8. Microtox® Bioassay Testing System.

9. Saylor GL, Chen L, Kupferle MJ (2013) Time varying toxicity of effluents from the electrochemical oxidation of phenol. Procedia Environmental Sciences 18: 451-463.

10. Interlab® Supply. Polyseed.

11. THAMNOTOXKIT F ${ }^{\mathrm{TM}}$ MICROBIOTESTS With the crustacean Thamnocephalus platyurus.

12. Donaldson K, Poland CA (2013) Nanotoxicity: challenging the myth of nanospecific toxicity. Curr Opin Biotechnol.

13. Li JH, Liu XR, Zhang Y, Tian FF, Zhao GY, et al. (2012) Toxicity of nano zinc oxide to mitochondria. Toxicology Research 1: 137-144.

14. Li M, Lin D, Zhu L (2013) Effects of water chemistry on the dissolution of ZnO nanoparticles and their toxicity to Escherichia coli. Environ Pollut 173: 97-102.

15. Recillas S, García A, González E, Casals E, Puntes V, et al. (2011) Use of $\mathrm{CeO}_{2}, \mathrm{TiO}_{2}$ and $\mathrm{Fe}_{3} \mathrm{O}_{4}$ nanoparticles for the removal of lead from water: toxicity of nanoparticles and derived compounds. Desalination, 277: 213-220.

16. Sergent JA, Paget V, Chevillard S (2012) Toxicity and genotoxicity of nano$\mathrm{SiO} 2$ on human epithelial intestinal HT-29 cell line. Ann Occup Hyg 56: 622 630.

17. Sasidharan A, Panchakarla LS, Chandran P, Menon D, Nair S, et al. (2011) Differential nano-bio interactions and toxicity effects of pristine versus functionalized graphene. Nanoscale 3: 2461-2464

18. Pompa PP, Vecchio G, Galeone A, Brunetti V, Maiorano G, et al. (2011) Physical assessment of toxicology at nanoscale: nano dose-metrics and toxicity factor. Nanoscale 3: 2889-2897. 